\title{
Seroprevalence of Human Brucellosis in and Around Puducherry: Application of an Immunocapture Agglutination Technique (Brucellacapt)
}

\section{Selvaraj Stephen*, Jothimani Pradeep, Balakrishnan Sangeetha and Shanmugam Jayaraman}

Department of Microbiology, Mahatma Gandhi Medical College \& Research Institute, Sri Balaji Vidyapeeth (Deemed-to-be-University) Puducherry - 607 402, India.

\begin{abstract}
The objective of the present study was the serological diagnosis of human brucellosis in and around Puducherry by application of Immunocapture-agglutination technique (Brucella Capt), which has been validated and found to be quite satisfactory. The study has included febrile patients, patients with chronic back pain/arthritis, healthy pregnant women, personnel exposed to domestic livestock and voluntary blood donors. Prevalence of brucellosis in these different categories was studied. Overall seroprevalence of brucellosis among different categories of individuals from Puducherry is very low, viz., 3.27\%. Among febrile patients, the prevalence is almost the same with $3.33 \%$ positivity. Among 100 healthy pregnant women, only one had antibodies to Brucella abortus (1.00\%). The category of animal handlers as expected had higher seroprevalence rate of $8.00 \%$. All the 45 voluntary blood donors were seronegative for brucellosis.

Keywords: Human Brucellosis, Agglutination, Brucella abortus, Puducherry.
\end{abstract}

*Correspondence: stephens4950@gmail.com; 91+ 9894383368

(Received: 19 January 2019; accepted: 06 March 2019)

Citation: Selvaraj Stephen, Jothimani Pradeep, Balakrishnan Sangeetha and Shanmugam Jayaraman, 'Seroprevalence of Human Brucellosis in and Around Puducherry: Application of an Immunocapture Agglutination Technique (Brucellacapt)', J Pure Appl Microbiol., 2019; 13(1):313-317 doi: 10.22207/JPAM.13.1.34

C The Author(s) 2019. Open Access. This article is distributed under the terms of the Creative Commons Attribution 4.0 International License which permits unrestricted use, sharing, distribution, and reproduction in any medium, provided you give appropriate credit to the original author(s) and the source, provide a link to the Creative Commons license, and indicate if changes were made. 


\section{INTRODUCTION}

Brucellosis is a major zoonotic disease transmitted by the domestic livestock to humans. Man can be infected by consumption of unpasteurized milk/milk products or inhalation of the infected aerosol, generated at the time of parturition of the livestock ${ }^{1-3}$. Although there are 12 recognized Brucella species, Brucella abortus, Brucella melitensis and Brucella suis are the major pathogens for humans with substantial morbidity and disability ${ }^{1-2}$. Human brucellosis has been reported in India and abroad with varying percentages. It has been reported from different parts of India with the prevalence ranging from 0.80 to $46.35 \%$ during the past 40 years $^{4-22}$. Recently, brucellosis has been included among the 11 prioritized zoonotic infections in India ${ }^{1}$. Clinical manifestations are protean in nature, with Pyrexia of Unknown Origin (PUO) as an important feature. Other signs and symptoms include chronic low back pain, arthritis, neurological manifestations, hepatosplenomegaly, Bad obstetric history (BOH)/abortions etc. ${ }^{1-2,20}$. According to Mantur and Amarnath ${ }^{3}$, the complications of neurobrucellosis may lead to encephalitis, meningitis, meningoencephalitis, peripheral neuritis and facial palsy with hemiplegia. Culture for Brucella, although a "Gold Standard" is laborious and requires 45 days to report as negative by the manual method in the Biphasic Brain Heart Infusion medium. ${ }^{2}$ In the automated culture by VITEK-2, results may be fairly quicker within a week or two ${ }^{23}$. Hence, serology is most commonly used for diagnosing the cases as well as in seroprevalence studies. Different serological tests are employed for the diagnosis of human brucellosis like Standard Agglutination Test (SAT) $)^{5,7,9-12,14-15}$. Rose Bengal Plate Agglutination Test (RBPT) $)^{6,7,10,11,14-15}$. Enzyme Linked Immunosorbent Assay (ELISA) ${ }^{6,16-19,23}$. Coombs test ${ }^{23}$ and Immunocapture-agglutination technique (Brucella Capt) ${ }^{8,24-26}$. Molecular tests are quite helpful for diagnosing and conforming human brucellosis by targeting and detection species level specific genes ${ }^{8,13}$.

\section{MATERIALS AND METHODS}

An investigative laboratory based study was conducted with archived and anonymised samples in the Department of Microbiology,
Mahatma Gandhi Medical College \& Research Institute (MGMC \& RI), Sri Balaji Vidyapeeth (Deemed-to-be-University), Pondicherry. After getting approval from the Institutional Human Ethical Committee (IHEC), MGMC \& RI. The study period was between December 2013 to August 2018. Sample size calculation was based on the national average as well as average in the southern states. The present seroprevalence of brucellosis in India and different parts of South India is different and much lower when compared to early seventies and eighties. Sample size (n) was calculated using the formula:

$$
\text { " } \mathrm{n}=\left[\mathrm{t}^{2} \times \mathrm{p}(1-\mathrm{p})\right] / \mathrm{m}^{2} \text { ", }
$$

Where $t=$ confidence level at $95 \%, p=$ estimated prevalence of the disease, $m=$ margin of error at $5 \%$.

With the prevalence rate of $11.26 \%$, based on the seroprevalence of human brucellosis in the last 15 years (2000-2015), the calculated sample size was 154 . We have taken a larger size of 300 patients and 220 as controls. Thus, 520 archived serum samples were included in the study after anonymising.

\section{Categories of participants}

Three hundred blood samples left over after completion of the laboratory investigations from patients with PUO/Hepatomegaly/ Splenomegaly/Patients with neurological disease/ chronic back pain/arthritis

Seventy five serum samples from animal handlers (veterinarians, butchers, slaughter-house workers, household contacts with domestic livestock)

Forty five healthy voluntary blood donors One hundred healthy ante-natal women

\section{Brucella Capt (Vircell Microbiologists, Spain)}

One-step Immunocapture assay was used for the identification of total brucella antibodies (IgM/IgG/IgA). The procedure was as outlined in the technical brochure of the kit. Briefly, all the reagents, test plates and serum samples were brought to room temperature before performing the test. The test plate contains U-bottom wells which are coated with anti-human immunoglobulins. Based on the kit recommendation for screening procedure, two doubling dilutions of serum samples were prepared viz., 1:160 and 1:320. Fifty microlitre of diluted serum samples, positive, negative controls 
were added to the plate. This was followed by the addition of $50 \mu$ l of the bacterial suspension (stained Brucella abortus suspension treated with formaldehyde) into all the wells and mixed well by shaking the plates. The plates were sealed with adhesive tape and incubated for 24 hours at $37^{\circ} \mathrm{C}$, in a dark humidity chamber protected from light exposure.

The test results were positive if the agglutination covers the whole well surface.

A button at the center of the well indicates the negative result (Fig. 1 ). Titre $\geq 1: 160$ was taken as positive.

Table 1. Antibody titres to Brucella abortus by Brucella Capt in different categories $(n=17)$

\begin{tabular}{lll}
\hline S.No. & Titre & $\begin{array}{l}\text { Categories of } \\
\text { Participants }\end{array}$ \\
\hline $1-8$ & $1: 160$ & Patients with FUO \\
9 & $1: 320$ & Patients with FUO \\
10 & $1: 2560$ & Patients with FUO \\
$11-15$ & $1: 160$ & Animal Handlers \\
16 & $1: 320$ & Animal Handlers \\
17 & $1: 160$ & Ante-natal Women \\
\hline
\end{tabular}

\section{RESULTS}

Overall seroprevalence of total Brucella antibodies was 17 (3.27\%) out of 520 subjects. Table 1 shows the details of antibody titres to Brucella abortus by Brucella Capt among different participants. Among the 300 febrile patients 10 (3.33\%) were positive. Eight patients had titres of 1:160, one patient each had 1:320 and 1:2560 respectively. Out of 75 animal handlers, six were seropositive $(8.00 \%)$ which comprises of five butchers who had titres of 1:160 and one farmer with a titre of 1:320. Only one healthy pregnant woman was seropositive for brucellosis (1.00\%) with a titre of 1:160. None of the voluntary blood donors were positive in Brucella Capt agglutination test. Remaining 503 participants were negative for brucella antibodies.

\section{DISCUSSION \\ Validation of Brucella Capt by different Researchers}

Brucella Capt, an Immunocapture agglutination test was validated by both overseas as well as Indian researchers with highly satisfactory

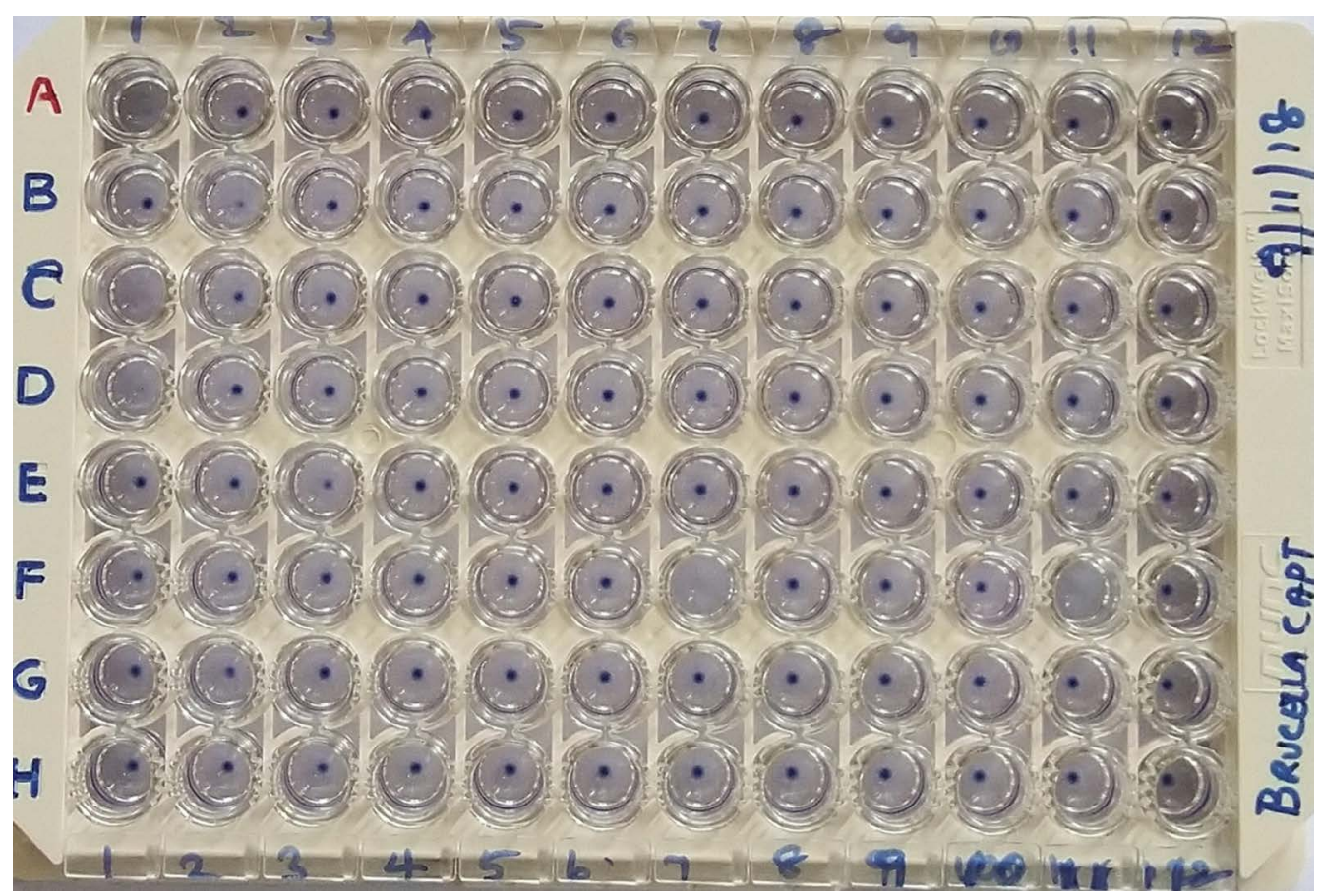

Fig. 1. Brucella Capt - Immunocapture Agglutination Technique

Well A1 and B1 - Positive and Negative controls; Well F7 and F11 - Test positive for Brucella antibodies 
performance ${ }^{8,23-26}$. According to the interpretation of the kit manufacturer, the significant titre is $\geq 1: 320 .{ }^{26}$ However a titre of $\geq 1: 160$ as serological evidence of brucellosis has been considered by Gomez et al ${ }^{24}$ and Oruduna et al., ${ }^{25}$ who reported $95.2 \%$ sensitivity and $100 \%$ specificity for Brucella Capt assay. We have also taken a titre of $\geq 1$ :160 as significant.

Seroprevalence of brucellosis among febrile patients (PUO)

In Indian subcontinent, brucellosis is considered to be an endemic zoonosis, which has been reported from every state of India. ${ }^{3-23}$ Thus a seroprevalence of $11.5 \%$ was found in Andhra Pradesh and 6.5\% in Orissa. ${ }^{21-22}$ In South and North Karnataka, 2.14\%, 0.92\% seropositivity was observed respectively among patients with or without fever and those presenting other symptoms for brucellosis ${ }^{17}$. Mangalgi et al. ${ }^{27}$ conducted a seroepidemiological survey in three districts of Karnataka viz., Bijapur, Bagalkot, and Gulbarga. They divided into two groups namely, directly exposed and indirectly exposed to animal contacts. Of the 1,733 subjects screened, 998 were grouped in group I and 735 in group II. Significant titers by SAT $(\geq 160)$ and $2-\mathrm{ME}(\geq 80)$ test were noted in 133 (13.3\%) and 99 (9.9\%) individuals in group I and three $(0.4 \%)$ individuals in group II. In the present study a very low seroprevalence of $3.3 \%$ was observed in people of Puducherry and neighbouring Tamil Nadu with symptoms of PUO. Seroprevalence of brucellosis among ante-natal women

Mantur et al. $^{3}$ from Belgaum, reported three cases of ante-natal women who suffered from Brucellosis. In our study, only one out of 100 healthy pregnant women was seropositive for brucellosis with a titre of $1: 160$. It is to be stressed here that even the next higher titre of 1:320 does not necessarily confirm active brucellosis and needs clinical correlation.

\section{Seroprevalence of brucellosis among animal handlers}

In Central Kerala, the overall seroprevalence is about $1.6 \%$ which comprises of general population and veterinary students with $2.45 \%$ and $1.14 \%$ seropositivity respectively ${ }^{7}$. Recently, Shome et al. ${ }^{17}$ from Karnataka reported overall prevalence of $7.04 \%$ among veterinary health care professionals. In our study $8.00 \%$ animal handlers were seropositive for brucellosis. Mangalgi et al. ${ }^{15}$ reported that the incidence rate was high when ingestion of raw milk regularly than the direct contact with domestic livestock.

Seroprevalence of brucellosis among Blood donors

Vaishnavi et al. ${ }^{20}$ from Chandigarh reported that only $0.36 \%$ of voluntary blood donors were seropositive for brucellosis with a titre of $1: 160$ by STAT. A study from Maharashtra found $52.63 \%$ RBPT positive donors with background low titre at 1:80 in STAT and 5.91\% positivity was confirmed by RBPT ${ }^{15}$. Sero-prevalence study from Bangalore documented a very low seropositivity of brucellosis (1.1\%) by using STAT ${ }^{10}$. An Iranian study found that $0.33 \%$ had low level of titres but $0.11 \%$ were confirmed as true positive for Brucella antibodies ${ }^{28}$. In the present study none of the voluntary blood donors were seropositive for Brucellosis.

\section{CONCLUSION}

The seroprevalence of human brucellosis in Puducherry is very low. This could be because of consumption of pasteurized milk and other dairy products by the people. Drinking unpasteurized raw milk is not the common custom in this part of South India. Brucella Capt kit has performed well in our experience like similar reports from Indian and Overseas researchers.

\section{ACKNOWLEDGEMENT}

The authors acknowledge with thanks the financial support and encouragement provided by the Chairman, Vice-Chancellor, Dean (Faculty of Medicine) and Dean (Research \& Allied Health Sciences) of MGMC \& RI, Sri Balaji Vidyapeeth (Deemed-to be- University) for providing SBV Faculty Research Fund to the First author (SS).

\section{CONFLICT OF INTEREST}

The author declares that there are no conflict of interest.

\section{REFERENCES}

1. Centre for Disease Control and Prevention, Brucellosis Reference Guide: Exposures, Testing And Prevention. https://www.cdc.gov/brucell-osis/pdf/brucellosireference-guide.pdf

2. Alton GG, Jones LM, Pietz DE. Laboratory techniques in brucellosis. 2nd ed. Geneva, Switzerland: World 
Health Organization; 1975.

3. Mantur BG, Amarnath SK. Brucellosis in India-a review. J. Biosci., 2008; 33(4): 539-47.

4. Stephen S, Indirani R, Rao KN. Brucellosis in coastal Karnataka. Indian J. Microbiol., 1978; 18: 28-31.

5. Kadri, S.M, Rukhsana A, Laharwal, M.A, Tanvir M. Seroprevalence of brucellosis in Kashmir (India) among patients with pyrexia of unknown origin; J. Indian Med. Assoc., 2000; 98: 170-1.

6. Thakur SD, Thapliyal DC. Seroprevalence of brucellosis in man; J. Commun. Dis., 2002; 34: 106-109.

7. Ajay Kumar V.J, Nanu E. Sero-Positivity of Brucellosis In Human Beings. Indian J. Public Health, 2005; 49(1): 22-4.

8. Annapurna SA, Mahavir Joshi. Serodiagnosis of Brucellosis- A Conventional and Molecular Approach. Asian Journal of Microbiology, Biotechnology \& Environmental Sciences Paper, 2012; 14(4): 583-690.

9. Almuneef MA, Memish ZA, Balkhy HH, Alotaibi B, AlgodaS, Abbas $M$, et al. Importance of screening household members of acute brucellosis cases in endemic areas. Epidemiol. Infect., 2004; 132: 533-40.

10. Nagarathna S, Sharmada S, Veena Kumari HB, Arvind $\mathrm{N}$, Sundar P, Sangeetha S. Seroprevalence of Brucella agglutinins: A pilot study. Indian J. Pathol Microbiol., 2009; 52: 457-8.

11. Yohannes M, Gill JP. Seroepidemiological survey of human brucellosis in and around Ludhiana, India. Emerg Health Threats J., 2011; 4: 7361.

12. Appannanavar SB, Sharma K, Verma S, Sharma M. Seroprevalence of brucellosis: A 10-year experience at a tertiary care center in North India. Indian J. Pathol and Microbiol., 2012; 55: 271-2.

13. Barua A, Kumar A, Thavaselvam D, Mangalgi S, Prakash A, Tiwari S, Arora S, Sathyaseelan K. Isolation \& characterization of Brucella melitensis isolated from patients suspected for human brucellosis in India. Indian J. Med. Res., 2016; 143: 652-8.

14. Kavi A, Shivamallappa SM, Metgud SC, Pati VD. An epidemiological study of brucellosis in rural area of North Karnataka. Int. J Med. Sci. Public Health, 2015; 4: 1197-1201.

15. Mangalgi S, Sajjan A, Mohite ST. Seroprevalence of Brucellosis among Blood Donors of Satara District, Maharashtra. Journal of Krishna Institute of Medical Sciences University, 2012; 1(1): 55-60.

16. Sharma HK, Kotwal SK, Singh DK, Malik MA, Kumar A, Rajagunalan, Singh M. Seroprevalence of human brucellosis in and around Jammu, India, using different serological tests. Veterinary World, 2016; 9(7): 742-6.

17. Shome R, Kalleshamurthy $T$, Shankaranarayana PB,
Giribattanvar $\mathrm{P}$, Chandrashekar N, Mohandoss N, Shome BR, Kumar A, Barbuddhe SB, Rahman H. Prevalence and risk factors of brucellosis among veterinary health care professionals. Pathog. Glob. Health, 2017; 111(5): 234-9.

18. Patil DP, Ajantha GS, Shubhada C, Jain PA, Kalabhavi A, Shetty PC, Hosamani M, Appannanavar S, Kulkarni RD. Trend of human brucellosis over a decade at tertiary care centre in North Karnataka. Indian J. Med Microbiol., 2016; 34(4): 427-32.

19. Pathak AD, Dubal ZB, Doijad S, Raorane A, Rodrigues A, Naik R, Naik-Gaonkar S, Kalorey DR, Kurkure NV, Naik $\mathrm{R}$, Barbuddhe SB. Human brucellosis among pyrexia of unknown origin cases and occupationally exposed individuals in Goa Region, India. Emerg Health Threats J., 2014; 7(1): 23846.

20. Vaishnavi C, Kumar S. Investigation for Background Prevalence of Brucella Agglutinins among Blood Donors. Indian J. Med. Microbiol., 2007; 25(3): 302-4.

21. Mrunalini N, Reddy MS, Ramasastry P, Rao MR. Seroepidemiology of human brucellosis in Andhra Pradesh. Indian Vet. J., 2004; 81(7): 744-7.

22. Mohanty TN, Panda SN, Das BR, Pradhan SK, Pradhan RK. Sero-incidence of brucellosis among dairy farm workers in Orissa. Indian Vet. J., 2000; 77(7): 568-70.

23. Sukumaran ST, Thayyil SS, Ambramoli SK. Acute brucellosis caused by Brucella melitensis: A case report. J. Acad. Clin. Microbiol., 2013; 15: 66-8

24. Gqmez, M. C., Nieto, J. A., Rosa, C., Geijo, P., Escribano, M. A., Muooz, A., \& Lqpez, C. Evaluation of seven tests for diagnosis of human brucellosis in an area where the disease is endemic. Clin. vaccine immunol., 2008; 15(6): 1031-3.

25. Orduna A, Almaraz A, Prado A, Gutierrez MP, GarciaPascual A, Duenas A, Cuervo M, Abad R, Hernandez $B$, Lorenzo B, Bratos MA, Torres AR. Evaluation of an Immunocapture-Agglutination Test (Brucellacapt) for Serodiagnosis of Human Brucellosis. J. Clin Microbiol., 2000; 38(11): 4000-5.

26. Casaoa MA, Navarroa E, Solera J. Evaluation of Brucellacapt for the diagnosis of human brucellosis. Journal of Infection, 2004; 49: 102-8.

27. Mangalgi SS, Sajjan AG, Mohite ST, Kakade SV. Serological, Clinical, and Epidemiological Profile of Human Brucellosis in Rural India. Indian J. Community Med., 2015; 40: 163-7.

28. Sofian M, Sheikholeslami M, Mahdaviani FA, Aghakhani A, Banifazl M, Eslamifar A, Sarmadian H, Deiri G, Ramezani A. Low Prevalence of Brucella agglutinins in Blood Donors in Central Province of Iran. Iran. J. Microbiol., 2013; 5: 24-7. 